NBER WORKING PAPER SERIES

\title{
DID THE AFFORDABLE CARE ACT YOUNG ADULT PROVISION AFFECT LABOR MARKET OUTCOMES? ANALYSIS USING TAX DATA
}

\author{
Bradley Heim \\ Ithai Lurie \\ Kosali Simon \\ Working Paper 23471 \\ http://www.nber.org/papers/w23471 \\ NATIONAL BUREAU OF ECONOMIC RESEARCH \\ 1050 Massachusetts Avenue \\ Cambridge, MA 02138 \\ June 2017
}

The views expressed are those of the authors and are not necessarily those of the U.S. Department of the Treasury (USDT) or the National Bureau of Economic Research. We thank Angshuman Gooptu and Kate Yang for research assistance. This paper has undergone review at the USDT. We thank Jeff Brown, Janet McCubbin, and participants of the 2014 Tax Policy and the Economy conference for helpful comments. A preliminary investigation that did not include regression analysis, titled "The Impact of the Affordable Care Act Young Adult Provision on Labor Market Outcomes: Evidence from Tax Data," was presented at the 2014 Tax Policy and the Economy conference, and is part of the conference volume Tax Policy and the Economy, Volume 29.

NBER working papers are circulated for discussion and comment purposes. They have not been peerreviewed or been subject to the review by the NBER Board of Directors that accompanies official NBER publications.

(C) 2017 by Bradley Heim, Ithai Lurie, and Kosali Simon. All rights reserved. Short sections of text, not to exceed two paragraphs, may be quoted without explicit permission provided that full credit, including $\odot$ notice, is given to the source. 
Did the Affordable Care Act Young Adult Provision Affect Labor Market Outcomes? Analysis Using Tax Data

Bradley Heim, Ithai Lurie, and Kosali Simon

NBER Working Paper No. 23471

June 2017

JEL No. I13,J01

\begin{abstract}
We study the impact of the Affordable Care Act (ACA) young adult dependent coverage requirement on labor market-related outcomes, including measures of employment status, job characteristics, and post-secondary education, using a data set of U.S. tax records spanning 2008-2013. We find that the ACA provision did not result in substantial changes in labor market outcomes. Our results show that employment and self-employment were not statistically significantly affected. While we find some evidence of increased likelihood of young adults earning lower wages, not receiving fringe benefits, enrolling as full-time or graduate students, and young men being self-employed, the magnitudes imply extremely small impacts on these outcomes in absolute terms and when compared to other estimates in the literature. These results are consistent with health insurance being less salient to young adults when making labor market decisions compared to other populations.
\end{abstract}

Bradley Heim

School of Public and Environmental Affairs

Indiana University

1315 E 10th St

Bloomington, IN 47405

heimb@indiana.edu

Ithai Lurie

Department of the Treasury

1500 Pennsylvania Avenue NW

Washington, DC 20220

Ithai.Lurie@treasury.gov
Kosali Simon

School of Public and Environmental Affairs

Indiana University

Rm 443

1315 East Tenth Street

Bloomington, IN 47405-1701

and NBER

simonkos@indiana.edu 
A growing literature draws attention to the effects of health insurance expansions on outcomes other than health insurance coverage and access to medical care, and important questions concerning the labor market consequences of new health insurance mandates continue to be debated. In this paper, we examine whether providing young adults with a source of health insurance unconnected to their own employment (through their parents' insurance plans) may affect work attachment, affect job characteristics, or encourage educational enrollment.

As an early provision of the Affordable Care Act (ACA), insurers and sponsors of selfinsured plans were required to allow dependents up to age 26 to remain on their parents' private health insurance policies. Prior to the passage of this provision of the ACA, employer-sponsored health insurance benefits for dependents were only excludable from federal income taxes if the dependent was under age 19, or under age 24 and a full-time student, and so health insurance policies often limited dependent coverage to young adults who satisfied these criteria. Those who were not eligible for parental insurance could either purchase health insurance through their own employer (or their spouse's employer, if married), purchase insurance in the non-group market, enroll in Medicare or Medicaid if disabled or if their income was sufficiently low, or be uninsured.

Though several studies have found that this provision increased insurance coverage among those under age 26, few studies have examined labor market outcomes, and all have methodological weaknesses. Compared to the extant literature, our work examines new outcomes that have not been studied to date, uses larger and better measured data than previously available, and uses a method that explicitly estimates effects among young adults whose parents have access to employer provided benefits. 
By making parental health insurance an option for young adults up to the age of 26, the ACA young adult provision may reduce the incentive to work in employment arrangements that offer employer health insurance, and may also reduce labor supply through an income effect. In addition, the availability of an alternative source of health insurance might make young adults more likely to undertake activities that involve lower labor force attachment (such as enrollment in post-secondary education). On the other hand, the YA provision might reduce the incentive to be a full-time student among those age 19-23, as those individuals could now stay on their parents' plan even if they weren't enrolled as a full-time student. However, young adults may place little value on the availability of health insurance, either because they are in good health and so face low insurance costs, or because they feel invincible and do not consider health insurance to be necessary, which may mute any labor market effects of gaining insurance.

Longitudinally linked tax data spanning 2008-2013 provide a unique opportunity to study labor market outcomes of the YA provision. Using data self-reported under penalty of law among tax return filers (Form 1040) and data reported by third parties on wage statements (Form W-2), miscellaneous income statements (Form 1099-MISC), and tuition statements from colleges and universities (Form 1098-T), we are able to examine whether an individual works in the formal sector or is self-employed, his or her total annual wages and receipt of employerprovided retirement and health benefits, and his or her educational enrollment. Our paper is also the first to study any ACA labor market outcomes using tax data.

Using these data, we estimate reduced-form difference-in-differences (DD) specifications that compare young adults of slightly different ages over time, as in the prior literature. However, since DD effects may mute causal effects that occur only among those whose 
parents have employer insurance benefits, we also estimate specifications that only include young adults whose parents have access to employer-provided fringe benefits.

Studying the impact of the ACA young adult (YA) provision on labor market outcomes is important because this provision affects individuals during a crucial period of human capital formation, when those individuals are engaged in post-secondary education, attaining initial employment, and embarking on careers. In addition, studying the YA provision may help us understand the response of a key age group to the Health Insurance Marketplace and Medicaid expansions that followed in 2014 , as young adults were the age group least likely to carry health insurance prior to the reforms.

\section{Background and Literature Review}

Several studies have documented the impact of the ACA young adult provision on insurance and medical care access (e.g. Monheit et al., 2011; Sommers et al., 2013; Akosa Antwi et al., 2013; Barbaresco et al., 2015; Akosa Antwi et al., 2015; Busch et al., 2014; Saloner and Cook., 2014; Golberstein et al., in press). Further, a growing literature draws attention to the effects of health insurance expansions on outcomes other than health insurance coverage and access to medical care. In this section, we briefly survey the extensive literature on the effect of health insurance on labor outcomes in general, ${ }^{1}$ and the much more limited literature focused on young adults.

\footnotetext{
${ }^{1}$ See Dave et al. (2015) for a more detailed literature review. In addition to the papers noted here, Mulligan (2013), Sommers et al. (2013) and Heim and Lurie (2015) all study the impact of recent health market reforms on labor market outcomes.
} 
A substantial amount of research in health economics investigates the connection between health insurance and the labor market. One strand of this work focuses on the "job-lock" effect of public and private insurance (Madrian, 1994; Cooper and Monheit, 1993; Yelowitz, 1995; Kapur, 1998; Ham and Shore Sheppard, 2005; Strumpf, 2011; Decker and Selck, 2012; Pohl, 2014; Dave et al., 2015; Hamersma and Kim, 2009) and finds mixed evidence concerning the impact of access to a non-employer source of health insurance on job outcomes and labor supply. A small number of studies have also examined whether the availability of health insurance affects the decision to be self-employed, with Madrian and Lefgren (1998) and Wellington (2001) finding a significant effect, contrary to Holtz-Eakin et al.'s (1996) findings.

Another relevant strand of research examines the effect of health insurance benefits on wages, as the possibility of a compensating differential suggests that workers would accept lower wages in response to health insurance (e.g. Gruber, 1994; Kolstad and Kowalski, 2016; and others). These studies have also produced mixed evidence, perhaps because workers may take into account additional factors beyond wages or benefits when making employment choices. In addition to labor supply, labor demand could also be affected by a health insurance expansion. For example, employers may now find that young adults with access to parental insurance can be hired less expensively, and these employers may increase their demand for young adult workers in response. However, if workers bear the full incidence of employer-sponsored health insurance, the cost to the employer would not change. In this case, we would expect young adult workers to receive higher wages when the employer no longer has to provide this fringe benefit to employees covered by a parent's plan, resulting in unchanged labor demand.

The receipt of health insurance through a parent may affect labor market incentives through similar mechanisms as the receipt of Medicaid; neither derives from an employer and 
both are ostensibly "free." ${ }^{2}$ On the other hand, Medicaid eligibility is contingent on low income, and thus may have additional disincentives for labor supply that are absent in the receipt of parental coverage. Several recent studies examine the effect of Medicaid expansions in Oregon, Massachusetts, Tennessee, and Wisconsin (Baicker et al., 2014; Dague et al., 2014; Garthwaite et al., 2014; Kowalski and Kolstad, 2016) to anticipate possible effects of the ACA. The study with the most rigorous design, a random assignment experiment in Oregon that expanded Medicaid to adults below the federal poverty level, shows very little effect on labor supply or earnings as a result of receiving Medicaid (Baicker et al., 2014). Dague et al. (2014) find in Wisconsin that those who were not enrolled in the program due to a cap worked more than those who were able to enroll in Medicaid, but effect size ranged from modest to medium. Garthwaite et al. (2014) use the case of Tennessee and find extremely large increases in labor supply following loss of Medicaid coverage.

Though little work has been done on the impact of health insurance on educational choices, the literature in education economics does find that young adult educational enrollment is sensitive to outside options. Cascio and Narayan (2015) find that the low-skill biased technological change represented by fracking caused an increase in the high school drop-out rate among males, while Charles et al. (2015) find that the housing boom of the 2000s improved labor market outcomes and reduced college enrollment by marginal workers. However, improved job openings likely represent a more attractive reason to leave school relative to health insurance available through parents being a reason to stay in school longer.

\footnotetext{
${ }^{2}$ Of course, adding a child to a parent's plan may necessitate switching from an individual or individual plus one plan to a family plan, which likely increases health insurance costs for the parent. In addition, Depew and Bailey (2015) find that the ACA young adult provision led to an increase in premiums of 2.5-2.8 percent among plans that covered children relative to individual plans.
} 
While the literature on health insurance and labor has looked at subgroups such as those near retirement (Blau and Gilleskie, 2001; Strumpf, 2010; Kapur and Rogowski, 2007), those who are unemployed (Gruber and Madrian, 1995), and married women who have health insurance available through their husbands (Buchmueller and Valetta, 1999), no work prior to the passage of the ACA focuses on young adults, despite the implications for future earnings trajectories that would have resulted from such research. This omission can be explained by an earlier lack of policy variation that could be used to design a causal study.

Economic intuition formalized in prior literature such as Madrian (1994) suggests that providing access to health insurance through a parent would reduce the demand for health insurance through employment and thus reduce labor supply on extensive and intensive margins. Young adults would pursue alternatives to working full time for firms that offer benefits, such as self-employment, education, or leisure, as the opportunity costs of such activities would decrease. Those workers who no longer require employer-provided health insurance could experience wage gains as a result of the compensating wage differential for employer-provided benefits. Conversely, these workers may appear to have lower annual wages due to a reduction in hours or a shift towards employment that maximizes utility in ways other than financial remuneration. These effects would logically be present only for those whose parents have access to employer-provided health insurance, and employment effects may be larger for young adults who are past traditional college age and may otherwise pursue full-time employment. Recent evidence, however, shows that many individuals place very low value on public health insurance availability (Finkelstein et al 2015), and young adults are especially likely to have high myopia (Gruber, 2001) so any such labor market effects of gaining insurance may be muted. 
A few recent papers shed some light on the effect of insurance for young adults on a limited set of labor market outcomes. A recent study by Akosa Antwi et al. (2013) that examines the impact of the YA provision on health insurance also provides a cursory look at labor supply. Three papers utilize variation from state laws prior to the ACA. ${ }^{3}$ Dillender (2014) examines the long-term labor market consequences of insuring young adults through state dependent-coverage laws, and finds an increase in wages. Depew (2014) and Hahn and Yang (2016) estimate the impact of state laws on work outcomes. Depew's findings suggest state mandates cause a decrease only in the hours worked, not in the probability of employment, though Han and Yang find that labor supply decreased on both the intensive and extensive margins from the state mandates. Finally, two working papers examine the impact of the ACA provision on labor market outcomes. Bailey (Forthcoming) finds that the ACA YA law increased entrepreneurial activity, though the specifications generally did not pass placebo tests and so the estimates are not likely to be reliable, while Bailey and Chorniy (2016) find that the law did not have any impact on job lock.

In sum, there is a substantial literature on the connections between health insurance and labor market outcomes, though only a budding literature devoted to studying the labor market effects of extending health insurance coverage to young adults specifically. Compared to the extant literature, this paper studies a wider variety of outcomes, including employment, job characteristics, and educational attainment. Further, this study utilizes several methodological improvements, including estimating difference-in-differences models while focusing on those

\footnotetext{
${ }^{3}$ Although more than half the U.S. states had some young adult provision in place prior to the ACA, those laws have weaker requirements than the ACA YA provision. The majority of employer-provided health insurance is selfinsured and thus exempt from state mandates. State mandates also do not affect Internal Revenue Service (IRS) tax obligations, meaning that employers could not provide tax-exempt compensation when covering those over age 18 (unless disabled or under age 23 and a full-time student), a further constraint on state YA mandates' effectiveness. Many state laws contained other stipulations, such as requiring that covered dependents be full-time students or unmarried.
} 
whose parents are likely to have employer-sponsored insurance and thus potentially affected by the YA provision.

\section{Method}

Since almost all previous studies of the ACA YA provision use a difference-in-difference (DD) design comparing access outcomes after the law to outcomes before the law for those in the affected age group (usually 19-25 year olds) vs. those outside it (usually 27-29 year olds), we first estimate the impact of the YA provision by estimating a simple difference-in-differences specification. Similar to those previous studies, we compare those in treatment age to those outside treatment age (24-25 being treatment age and 27-29 being control age; 26 is excluded ${ }^{4}$ ) before and after the law, and estimate an equation of the form

$$
\text { Outcome }_{i t}=\beta_{1} \text { Young }_{i t}+\beta_{2} \text { Young }_{i t} \text { Post }_{i t}+\delta_{t}+\varepsilon_{i t}
$$

where Outcome $_{i t}$ is one of the labor market outcomes of interest, Young $i t$ denotes ages 24-25, Post $_{i t}$ denotes the years 2011-13, and $\delta_{t}$ is a year fixed effect. ${ }^{5}$ The coefficient of interest is $\beta_{2}$. We next conduct regression-adjusted versions of the DD calculations in which we account for the national annual unemployment rate, age fixed effects, and an interaction of age

\footnotetext{
${ }^{4}$ Ages are based upon the age at the end of the calendar year. We exclude 26 year olds, since such individuals could be in the treatment group (under 26) in some months of the year and in the control group (26 and over) in the other months. This problem is ameliorated somewhat by the fact that insurers are allowed to keep 26 year olds on parental plans until the end of the plan year (so some 26 year olds would belong in the treatment group), but this problem still exists for plans that do not end at the end of the calendar year. So, to keep such partially treated individuals out of the treatment and control groups, we omit the 26 year olds.

${ }^{5}$ Note that we do not include state fixed effects, as we cannot observe state of residence for those young adults who do not file tax returns and do not receive W-2 form or 1098-T forms.
} 
fixed effects and the national unemployment rate. The estimating equation for these specifications is

$$
\text { Outcome }_{i t}=\beta_{1} \text { Young }_{i t}+\beta_{2} \text { Young }_{i t}{ }^{*} \text { Oost }_{i t}+\gamma X_{i t}+\delta_{t}+\varepsilon_{i t}
$$

However, such a DD design suffers from the fact that, absent general equilibrium effects, the law should only impact those whose parents have employer-sponsored health insurance. As such, since some untreated young adults are included in the treatment group, they are unable to show in a convincing manner that the estimated impact of the YA provision arises among the treated group. To correct for this concern, one could in theory cut the estimation sample to include only those whose parents have employer-sponsored insurance to demonstrate that effects are being driven by these individuals. However, most data sets that have been used in prior studies do not contain information on non-co-resident parents, and so this distinction has not been possible. In our tax data which contains longitudinal links, however, we are able to utilize parental information on employer benefits to focus on the portion of those under 26 who are likely to be treated by the ACA YA provision. Thus, in our preferred specification, we reestimate our DD model, focusing on those whose parents are likely to be covered by employerbased health insurance. ${ }^{6}$ In addition to providing information on the impact of the YA provision

\footnotetext{
${ }^{6}$ Even though we have panel data, a specification that includes individual fixed effects is problematic, since the effect of the YA provision in such a specification would be identified solely off of the 1986 birth cohort. Note that including individuals fixed effects essentially de-means the data, and so the coefficient on Young*Post is identified only off of those for whom Young*Post is not always 0 or 1 . Young*Post always equals zero for birth cohorts from 1979-1985 (1979-1982 birth cohorts never have Young = 1, and birth cohorts from 1983-1985 have Young $=1$ only in the pre-period), while Young*Post always equals 1 for birth cohorts from 1987-1989. Only for the 1986 cohort does Young*Post equal in one year (2011) and 0 in another (2013).
} 
on labor market outcomes, such a specification also offers information on the reliability of estimates from DD designs that lack parental data. ${ }^{7}$

In all specifications, we exclude data from 2010 as a period of staggered implementation; some insurers complied as early as spring 2010, but as most insurance plans renewed on January $1^{\text {st }} 2011$, we consider this the full implementation date. We conduct statistical checks to ascertain that prior trends in labor markets are similar among the control and treatment ages, although, as we explain in the following section, we have limited years of data prior to policy implementation for these tests. Finally, because the identifying variation comes from a difference in policy by age group and year, we cluster standard errors at the age* year level.

\section{Data}

In this study, we use a panel of U.S. tax return data spanning 2008-2013, which was drawn from the population of U.S. income tax filers. Although such data have been used in prior tax and labor research (for example, Chetty et al., 2013), research has been limited by severely restricted

\footnotetext{
${ }^{7}$ An additional potential concern is that the period after the YA policy change coincides with a labor market recovery, and so any differential recovery patterns by age could be incorrectly estimated as having been caused by the YA provision, even if pre-trends tests did not signal concerns. Given that the law only affects young adults whose parents have private insurance, young adults whose parents do not have employer benefits could form an additional control group in a triple difference (DDD) specification. The use of this additional control group would rest on the assumption that the law did not cause selection. There is evidence in the literature that the YA provision did not cause parents to seek insurance or change parental labor supply (Akosa Antwi et al., 2013; Depew, 2014), and a difference-in-differences specification similar to (2) in which the dependent variable was our proxy for parental health insurance suggested that the YA provision did not affect parental insurance coverage. However, the pre-trends tests failed in some of the triple difference specifications, suggesting that estimates of the effect of the YA provision in these specifications may not be reliable. Nevertheless, we tried such specifications and summarize these results below. Detailed results are available from the authors upon request.
} 
access, and the present study advances the literature by using these data to examine the labor market impacts of the ACA.

Since non-dependent children are not listed on their parents' tax form(s), and vice versa, it is not possible to link young adults and parents using only tax returns from recent years. However, a dependent file from 1997 matches the Social Security Numbers (SSNs) of primary and second filers to the SSNs of their dependent children, if any, ${ }^{8}$ which makes it possible to match parents' and children's information if those children were claimed as dependents in 1997. So, to create a dataset that links parents' and children's information, we gather filing and other tax information reporting from 2008-2013 for the children represented in the 1997 file, as well as information from their parents' W-2 forms; we then merge each young adult's information to that of the individuals listed as their parents in 1997.

Because individuals who were older than 18 years or younger than 2 years old in 1997 were less likely to be claimed as dependents in 1997 , we are only able to utilize information on birth cohorts from 1979 through 1995 when utilizing information on parental insurance. This structure means that we are limited in conducting pre-trends tests: we cannot go back farther than tax year 2008 and still have the full set of control individuals aged 27-29, which limits our pretrends tests to 2008-2009 (see Appendix Table 1).

Ideally, we would know for each year of our data (2008-2013) whether parents had access to employer-sponsored health insurance. Since 2012, employers with more than $250 \mathrm{~W}-2$ forms filed in the previous year have been required to report employer provision of health insurance on $\mathrm{W}-2$ s. However, since this requirement started in 2012, we only have this information beginning in that year. In addition, this ACA reporting requirement only applies to firms with more than

\footnotetext{
${ }^{8}$ Empirically, most children 18 and younger are claimed on a parent's tax returns, given the substantial tax benefits of claiming dependents. The dependent file, which is based on claiming dependents on tax returns, is comprehensive in tax year 1997 and from 2001 forward but is very limited in tax years 1996 and 1998-2000.
} 
250 workers, while approximately $40 \%$ of the U.S. workforce is employed in firms with fewer than 250 workers. ${ }^{9}$ By our (unreported) calculations using publicly available data from the Medical Expenditure Survey (MEPS) Insurance Component, however, it does appear that compliance with this requirement by large firms is high. We tried backfilling data on employer provision of health insurance for years prior to 2012 using the following steps: from 2012 data, we know whether an employer with a certain Employer Identification Number (EIN) offers health insurance if any of the workers of that EIN have a W-2 form that reports health insurance. From that, we create a data set of EINs known to offer health insurance in 2012. Under the assumptions that these employers also offered health insurance during 2008-2011, and that they offer insurance to all their workers when they offer to any, we have information on employer health insurance offers for 2008-2013. However, when we examine these data, we found that the rate of employer health insurance increases sharply over time, which might be expected because our method of imputing works best for more recent data. Even though data missing at random would not pose a large threat to identification, our use of an imputation method for years before 2012 implies caution would be advisable in using this measure.

As an alternative method of determining coverage, we use information on whether parents have employer-sponsored retirement plans. Participation in an employer's retirement plan is recorded on W-2 forms in all years of our data (and is available for all employers). Further, tabulations from the CPS and the MEPS suggest that more than $90 \%$ of families in which at least one parent had an employer-sponsored retirement plan were also covered by employer-sponsored insurance (ESI); accordingly, we use participation in a retirement plan as a proxy for parental

\footnotetext{
${ }^{9}$ Author calculations using data at http://www.bls.gov/web/cewbd/table_f.txt The calculation shows that in Q1 2013, 51.6M worked in private firms with fewer than 250 employees, out of a total payroll number of $135.7 \mathrm{M}$ (from https://ycharts.com/indicators/total_nonfarm_payrolls).
} 
availability of health insurance. Note that, in this specification, the retirement plan participation proxy for health insurance coverage is used for all individuals, not just those who worked for small firms. However, around $20 \%$ of families in the MEPS who do not have employersponsored retirement plans are also covered by ESI. For this reason, not contributing to a retirement plan is a weaker proxy for lack of health insurance. ${ }^{10}$

The outcomes that we analyze fall into three groups: employment status (including whether the individual received a W-2 form indicating receipt of wage and salary income, and whether the individual received any amount of self-employment income reported either on Schedule SE or on 1099-MISC forms); ${ }^{11}$ job characteristics from W-2 forms (including log annual wage income, whether the individual's primary ${ }^{12}$ employer offered health insurance, and whether the individual had a retirement plan through his or her primary employer); and educational enrollment from 1098- forms $^{13}$ (including whether the individual was a student at a postsecondary institution, whether he or she was a full-time student at such an institution, and whether he or she was a graduate student at such an institution). A potential concern occurs if individuals select into the sample due to a change in filing behavior in reaction to the policy

\footnotetext{
${ }^{10}$ Another proxy would have been full-time employment in a large firm. However, tax data do not contain information on hours of work.

${ }^{11}$ It is well established self-employment income is underreported in tax data, and so this variable may miss some individuals who are self-employed. However, Hurst, Li, and Pugsley (2014) find that misreporting of selfemployment income plagues survey data as well, and estimate that self-employment income is underreported by about 25\% in the Consumer Expenditure Survey and the Panel Study of Income Dynamics,

${ }^{12}$ We define the primary employer (job) as the employer (job) from which the individual receives the most in wages in a given year.

${ }^{13}$ The instructions for Form 1098-T note that this form is required to be filed by any "college, university, vocational school, or other postsecondary educational institution that is described in section 481 of the Higher Education Act of 1965 as in effect on August 5, 1997, and that is eligible to participate in the Department of Education's student aid programs. This includes most accredited public, nonprofit, and private postsecondary institutions." The educational institution files this form for any students who are enrolled for credit and who pay a qualified tuition or related expense. Educational institutions are not required to file the form for students whose expenses are entirely waived or paid entirely with scholarships. As a result, if a student has a full scholarship, or if a student is a graduate student whose tuition is waived, he or she might not have received a 1098-T, in which case we would wrongly assume that the individual was not a student.
} 
changes studied here. However, most of our outcome variables come from forms that are filed regardless of whether the person filed an income tax return. ${ }^{14}$

For our analysis, we use a 1\% sample of the population of 1997 parent-child matches, consisting of 571,028 unique individuals who range in age from 13-29. When we limit to those of ages 24-29, excluding 26 year olds, and use all data on 2008-2013 except 2010, we obtain 823,249 person-year observations, corresponding to about 361,179 unique individuals. ${ }^{15} \mathrm{We}$ examined the breakdown of our sample by year and age and observed that the number of individuals does not change in any systematic way over time as we construct a balanced panel. We do find, however, that the number of older young adults is consistently lower than the number of younger individuals. This is likely due to the fact that in 1997 those who were 17 and 18 years old were more likely to be already living outside of the parental household and not claimed as dependents. We conducted statistical tests to ensure that no systematic difference in sample size aligns with our main identification method, and found no evidence of systematic difference (for example, between treatment and control, before and after the policy, for the DD).

Table 1 presents sample statistics for three samples - 24-29 year olds, 24-29 year olds whose parents contributed to a retirement plan, and 22-29 year olds whose parents contributed to a retirement plan. In the sample of 24 to 29 year olds, 80.7 percent had some wage and salary income and 10.0 percent had some self-employment income; the primary employer offered health insurance for 46.2 percent and a retirement plan for 32.4 percent; and 19.4 percent were enrolled as post-secondary students. When the sample is cut to those whose parents contributed

\footnotetext{
${ }^{14}$ For example, job characteristic variables come from W-2 forms, which (in addition to being attached to income tax returns) are filed by employers with the IRS; some self-employment income comes from 1099MISC forms (which are also subject to third-party reporting); education variables come from1098-T forms (which are filed by colleges and universities with the IRS indicating that tuition payments were received on behalf of a student).

${ }^{15}$ See Appendix Table 2 for a breakdown of our sample by age and year. When the sample includes 22-29 year olds whose parents are likely to have health insurance, we have 651,222 person-year observations.
} 
to a retirement plan and so were likely to be covered by health insurance, the employment outcomes are generally higher, as more of this subsample have wage and salary income, are offered health insurance or a retirement plan, and are enrolled as post-secondary students. When 22-23 year olds are added to the sample of 24-29 year olds, the employment outcomes are generally lower, but enrollment as a post-secondary student is higher, as would be expected.

\section{Results}

\section{Full Sample Results}

Table 2 presents the results from our main specification. In Column 1, we present results from a simple difference-in-differences specification to examine the raw differences between the treatment and control groups, pre- and post-reform. Across outcomes, only one of the coefficients is statistically significant. The YA provision is estimated to have increased the prevalence of young adults working at a primary employer that offered health insurance by a marginally statistically significant 0.5 percentage points (or 1.1 percent). Note, however, that this effect is contrary to expectations given the theory discussed above.

This significant result is robust to including additional controls in Column 2. However, when controls are added, the YA provision is estimated to significantly impact a number of other labor market outcomes. The YA provision is now estimated to lead to young adults earning 1.8 percent lower annual wages. ${ }^{16}$ Further, consistent with theoretical expectations, young adults are

\footnotetext{
${ }^{16}$ Recall that this reduction in annual wages could be driven by some combination of lower hourly wages, lower annual hours, or both.
} 
estimated to be 0.5 percentage points (1.6 percent) less likely to work at an employer that offers a retirement plan, and a marginally statistically significant 0.2 percentage points ( 3.6 percent) more likely to attend graduate school. On the other hand, contrary to expectations, the fraction not earning any wage and salary income is estimated to have declined by 0.4 percentage points (2.3 percent), and the fraction attending post-secondary school of any type is estimated to have declined by 0.2 percentage points ( 0.8 percent).

As noted above, however, the estimation samples in these specifications include a number of individuals whose parents do not have employer-sponsored insurance, and so are not actually impacted by the ACA provision. In Column 3, then, we cut the sample to those who are likely to be "treated" by the YA provision by including only those whose parents have an employer-based retirement plan. This specification is our preferred specification.

When this is done, the effects on all outcomes are generally either consistent with theory or are statistically insignificant. In the top panel, the estimated impact on having any $\mathrm{W}-2$ forms and on reporting self-employment income are both statistically insignificant. In the second panel, the YA provision is estimated to decrease annual wages by 0.9 percent and decrease the fraction working at an employer that offers a retirement plan by 0.5 percentage points, while the impact on working at an employer that offers health insurance is now statistically insignificant. Finally, in the bottom panel, though the fraction of post-secondary students is estimated to have decreased by 0.2 percentage points, ( 1.5 percent), the fraction of full-time students increased by 0.5 percentage points ( 2.3 percent), and the fraction of graduate students increased by 0.3 percentage points ( 4.3 percent). 
Since full-time and graduate education are estimated to have increased, while overall post-secondary education is estimated to have marginally significantly decreased, these results imply that part-time schooling decreased. These results may indicate that the YA provision had an income effect that enabled students to attend school full rather than part time. Further, universities often mandate that full-time (but not part-time) students be covered by health insurance. Thus, the YA provision may have made it less expensive for students to satisfy this requirement and enroll full time.

Overall, these results suggest that the ACA YA provision did impact some of the labor market outcomes, albeit by modest margins. ${ }^{17}$

Of course, these estimates could be driven by differential pre-existing trends between the treatment and control groups. To examine whether this was the case, we test whether time trends in the outcomes differed between the treatment and control groups in the years prior to the policy change. These 'parallel trends tests' indicate whether there had been significantly divergent trends in outcomes even before the policy change, which would signal unreliability in the difference-in-difference estimates. Unfortunately, our data only contain two pre-reform years, and so we are only able to test for differential pre-reform trends in these two years.

The results of these tests are presented in Table $3 .{ }^{18}$ Reassuringly, for all of the specifications in Table 2, the differences in pre-policy trends are statistically insignificant.

\footnotetext{
${ }^{17}$ As noted above, we also tried triple difference specifications using two different proxies for the presence (or absence) of parental employer-sponsored insurance: the presence of a parental retirement plan in a given year, or the parent working for an employer that reported offering health insurance to any employee in 2012. Since these specifications measure the presence of parental ESI with error, the estimated effects may be downward biased. These specifications generally found insignificant effects of the YA provision on the outcomes studied, though the estimated effect on log annual wages, having an employer that offers a retirement plan, and being a graduate student were statistically significant and similar in magnitude to our preferred specification when the 2012 health insurance proxy was used. These results are available upon request from the authors.
} 
Nevertheless, since our pre-treatment period only contains two years, one might be concerned that pre-treatment trends differed in years prior to the start of our sample. However, Slusky (Forthcoming) finds that across a variety of commonly used data sets, the pre-policy trends are most similar for labor market outcomes when defining the treatment group as we do here, as those aged 24-25, and the treatment group as 27-29 year olds. Caution should be exercised if other age ranges are used in labor market analyses.

To examine the robustness of the results in our preferred specification to the choice of ages included in the sample, in Table 4 we expand the estimation sample to 22-29 year olds. When this is done, the results are generally similar to those when the 24-29 year old sample was used, with the YA provision estimated to have led to a 1.1-percent decrease in annual wages, a 0.3-percentage-point decline in working for a primary employer with a retirement plan, and a 1.1-percentage-point (3.7 percent) increase in full-time student status. The one qualitative difference in the two samples arises for being a post-secondary student, in which the coefficient switches sign and is now statistically insignificant.

\section{Results for Subsamples}

To examine whether the impact of the YA provision differed according to the demographic characteristics of the young adults it covered, in Table 5 we re-estimate our preferred specification (from Column 3 in Table 2), but split the sample according to whether the

\footnotetext{
${ }^{18}$ As noted above, since our data starts in 2008, the pre-treatment period contains only two years (2008-2009). In these pre-trends tests, age indicator variables, and the interaction between age and unemployment rate, were excluded due to multicollinearity in the limited pre-policy sample period.
} 
young adult is male or female, while in Table 6 we split the sample according to the income of the young adult's parents in 1997.

In Table 5, several differences by gender are apparent. The YA provision is estimated to have increased the likelihood that young men will earn self-employment income, which is consistent with theory. ${ }^{19}$ The declines in annual wages and in working for an employer with a retirement plan, on the other hand, are centered among women. ${ }^{20}$ Finally, both genders appear more likely to enroll in full-time post-secondary and graduate education (though the impact on graduate education is statistically insignificant for women). Thus, the ACA YA provision appears to have led young men to increase their education and self-employment, while it led women to increase their education while taking jobs with fewer fringe benefits and lower wages.

In Table 6, the sample is split according to whether the parents of the young adult had income of less than $125 \%$ of the federal poverty line (FPL), between $125 \%$ and $250 \%$ of FPL, between $250 \%$ and $400 \%$ of FPL, or in excess of $400 \%$ of FPL. Here, it appears that the impacts on self-employment and working for an employer who offered a retirement plan were centered among the highest income group, as was the decline in wages, ${ }^{21}$ though significant wrongly signed effects are found for the first two of these outcomes among the lowest income group. The impact of post-secondary enrollment overall is centered among the lowest income group, ${ }^{22}$

\footnotetext{
${ }^{19}$ This result is also consistent with the fact that self-employment is more prevalent among men than women. For example, see Pew Research Center (2015), which finds that $12 \%$ of male workers and $7 \%$ of female workers were self-employed in 2014.

${ }^{20}$ The larger effects for women may be driven by the fact that women tend to have higher health costs than men (Alemayehu and Warner (2004)), and have been found to be more risk-averse (see, for example, the survey in Croson and Gneezy (2009)), and so may value parental insurance more.

${ }^{21}$ This may be driven by young adults from high income families having greater access to parental resources that might be needed to start a new business or choose a lower-paying job.

22 The impact on the next highest income group, however, is wrongly signed. In addition, the wrongly signed effect for primary-employer-sponsored health insurance is centered among the lowest two income groups.
} 
though the impacts on full-time schooling and graduate school tend to be centered among higher income groups. $^{23}$

\section{Discussion}

Taken together, the results above suggest that the ACA YA provision did not significantly affect wage and salary employment or self-employment overall. However, some statistically significant effects that are consistent with predictions from theory were found, including a decline in log annual wages, an increase in being a full-time student or graduate student (though there was a marginally significant decline in being a post-secondary student), a decrease in wage and salary employment (among the 19-29-year-old sample), and an increase in self-employment (among men).

To gauge the size of our estimated impacts relative to other findings in the literature, in Table 7 we compare the elasticity with respect to gaining insurance through an alternate source implied by estimates from our preferred DD specification (using those whose parents had a retirement plan) to the largest statistically significant estimates available in the literature. To convert our reduced-form estimates into elasticities of the labor market outcome with respect to gaining health insurance, we utilize an estimate from Akosa Antwi et al. (2013) that found a 30 percent increase in dependent coverage due to the YA provision. ${ }^{24}$ We perform this comparison

\footnotetext{
${ }^{23}$ These results may be reflective of lower income young adults being more likely to be on the margin between attending and not attending post-secondary education, with higher income young adults being more likely to be on the margin between attending graduate school or not.

${ }^{24}$ Since the Akosa Antwi et al. (2013) estimate comes from studying the same age groups that were affected by the same policy during the same time period, their estimate should be applicable to our estimation sample. However,
} 
for four outcomes for which we could find a relevant literature: No W-2 Forms (wage and salary employment), Any Self-Employment Income (self-employed), Log Annual Wages, and FullTime Student.

Each of four literatures includes several studies (except for the Full-Time Student outcome, where Jung et al. (2013) is the only study we were able to find), and in almost all cases studies exist that find no statistically significant effects on relevant outcomes. Often the studies cited did not explicitly state an elasticity, and, as mentioned, our research did not estimate an insurance effect itself; thus these numbers should be viewed as back-of-the envelope calculations. Nonetheless, Table 7 shows our implied elasticities compared to the largest estimates available in the literature. In doing this comparison, it is important to note that two of the papers (Dague et al., 2014 and Garthwaite et al., 2014) do not specifically estimate impacts among young adults, so the differences in results could also be due to differences in the way health insurance affects labor market behavior for different ages. Nevertheless, our implied elasticity estimates are extremely small compared to the largest in the literature. Specifically, our implied elasticity for whether an individual works is a statistically insignificant 0.05 among 24-25 year olds, whereas the largest estimate in the literature (Garthwaite et al., 2014) finds an elasticity of 0.63 . For self-employment, our estimate among $24-25$-year-old men is 0.14 , much smaller than the largest estimate in the literature (0.8). Similarly, for log wages and for full-time student status, our estimates for all 24-25 year olds are small compared to the largest existing estimates (-0.03 vs -0.20 and 0.08 vs. 0.22$)$. Thus, even when we do estimate statistically

note that the estimate from this study comes from a sample of all young adults, not those whose parents had access to employer-sponsored insurance. Nevertheless, if we used estimates from the specification in Column 2 of Table 2, which (like Akosa Antwi et al., 2013) includes all young adults, the elasticities would be very similar, because the coefficients are very similar. 
significant coefficients, the estimated effects are nowhere near the upper bounds on the responses found elsewhere.

There are several caveats to our measures in the tax data. Most notably, we were unable to examine dependent health insurance as an outcome. However, almost all prior papers on the YA requirement have ascertained that the provision increased dependent coverage as intended, and we take as given that were this information reported, our method would also show an increase in dependent coverage. Estimates in Akosa Antwi et al. (2013, Table 2) show an approximately 30-percent increase in employer-dependent coverage for 19-25 year olds in the period after the law, compared to before the law. Nevertheless, having the outcome of dependent coverage in our data could enable us to provide a definitive estimate on the insurance impact of the law and ascertain an instrumental variable equivalent within the same data set.

\section{Conclusion}

There is very little evidence prior to the ACA regarding how access to health insurance affects the labor market and socioeconomic outcomes of young adults. Tax data provide a unique opportunity to estimate the impact of the ACA YA provision using a large sample of administratively reported data, and focusing on those whose parents were likely to have employer-sponsored insurance. Prior evidence on effects of the YA provision is limited, and shows a reduction in hours but no effect on employment or job lock. The outcomes we investigate are whether the individual worked in the formal sector, whether he or she was self- 
employed, total annual wages, whether he or she had employer-provided health and retirement benefits, and educational enrollment.

Taken as a whole, our results suggest that the YA provision did not substantially affect labor market behavior. Our results show that employment and self-employment were not statistically significantly affected in the sample overall. Further, though we find that the YA provision likely influenced young adults to earn less annually (through some combination of lower hours and/or lower wages), work for employers that were less likely to offer fringe benefits, enroll as full-time or graduate students, and (for young men) to be self-employed, our estimated impacts on all of these margins are relatively modest.

Although it is possible that labor market outcomes have changed in ways not captured by tax data (e.g. hours of work may change even while total wages do not, and non-reported selfemployment may change), our evidence suggests that the extension of health insurance to young adults has led to very modest impacts on labor market outcomes thus far.

Tax data have been used to study the labor market impacts of health insurance in the past (e.g. Heim and Lurie, 2010); however, this study is the first to use tax data to examine the effect of the ACA on labor market outcomes. Researchers will be able to analyze other features of the ACA with respect to public finance consequences as more years of these tax data become available. For example, this research can be extended to study health insurance changes and labor market outcomes for young adults who do not have access to parental benefits in response to Marketplace and Medicaid expansions that occurred in 2014. 


\section{$\underline{\text { References }}$}

Akosa Antwi, Yaa, Moriya, Asako S., and Simon, Kosali. 2013. "Effects of Federal Policy to Insure Young Adults: Evidence from the 2010 Affordable Care Act Dependent Coverage Mandate." American Economic Journal: Economic Policy 4(4):1-28.

Akosa Antwi, Yaa, Moriya, Asako S., and Simon, Kosali. 2015. "Access to Health Insurance and the Use of Inpatient Medical Care: Evidence from the Affordable Care Act Young Adult Mandate." Journal of Health Economics. 39(C):171-187.

Alemayehu, Berhanu, and Kenneth E. Warner. 2004. The lifetime distribution of health care costs. Health Services Research. 39(3): 627-42.

Baicker, Katherine, Amy Finkelstein, Jae Song, and Sarah Taubman. 2014. "The Impact of Medicaid on Labor Force Activity and Program Participation: Evidence from the Oregon Health Insurance Experiment.” American Economic Review. 104(5): 322-28.

Bailey, James, and Anna Chorniy. 2016. "Employer Provided Health Insurance and Job Mobility: Did the Affordable Care Act Reduce Job Lock?" Contemporary Economic Policy. 34(1): 173-183.

Bailey, James. Forthcoming. "Health Insurance and the Supply of Entrepreneurs: New Evidence from the Affordable Care Act's Dependent Coverage Mandate." Small Business Economics.

Barbaresco, Silvia, Charles J. Courtemanche, and Yanling Qi. 2015. "Impacts of the Affordable Care Act Dependent Coverage Provision on Health-related Outcomes of Young Adults." Journal of Health Economics. 40(C): 54-68

Blau, David M. and Donna B. Gilleskie. 2001. "Retiree Health Insurance and the Labor Force Behavior of Older Men in the 1990s." The Review of Economics and Statistics 83(1):64-80.

Buchmueller, Thomas C. and Robert G. Valletta. 1999. "The Effect of Health Insurance on Married Female Labor Supply.” Journal of Human Resources 34(1): 42-70.

Busch, Susan H., Ezra Golberstein, and Ellen Meara. 2014. "ACA Dependent Care Coverage Provision Reduced High Out-of-Pocket Health Care Spending.” Health Affairs 33(8):1361-1366.

Cantor, Joel C., Alan C. Monheit, Derek DeLia, and Kristen Lloyd. 2012. "Early Impact of the Affordable Care Act on Health Insurance Coverage of Young Adults." Health Services Research 47(5): 1773-1798.

Cascio, Elizabeth U. and Ayushi Narayan. 2015. "Who Needs a Fracking Education? The Educational Response to Low-Skill Biased Technological Change." NBER Working Paper 21359. 
Charles, Kerwin Kofi, Erik Hurst, and Matthew J. Notowidigdo. 2015. "Housing Booms and Busts, Labor Market Opportunities, and College Attendance.” NBER Working Paper 21587.

Chetty, Raj, John N. Friedman, and Emmanuel Saez. 2013. "Using Differences in Knowledge across Neighborhoods to Uncover the Impacts of the EITC on Earnings." American Economic Review 103(7): 2683-2721.

Cooper, Philip F. and Alan C. Monheit. 1993. "Does Employment-Related Health Insurance Inhibit Job Mobility?” Inquiry 30(4): 400-416

Croson, Rachel and Uri Gneezy. 2009. "Gender Differences in Preferences.” Journal of Economic Literature. 47(2): 1-27.

Currie, Janet and Brigitte C. Madrian. 1999. "Health, Health Insurance and the Labor Market" in O. Ashenfelter and D. Card (eds.), Handbook of Labor Economics: 3309-3416.

Dague, Laura, Thomas DeLeire, and Lindsey Leininger. 2014. "The Effect of Public Insurance Eligibility for Childless Adults on their Labor Supply.” NBER Working Paper 20111.

Dave, Dhaval, Sandra L. Decker, Robert Kaestner, and Kosali I. Simon. 2015. "The Effect of Medicaid Expansions in the Late 1980s and Early 1990s on the Labor Supply of Pregnant Women." American Journal of Health Economics. 1(2): 165-193.

Decker, Sandra and Frederic W. Selck. 2012. "The Effect of the Original Introduction of Medicaid on Welfare Participation and Female Labor Supply." Review of Economics of the Household 10(4): 541-556.

Depew, Briggs. 2015. "The Effect of State Dependent Mandate Laws on the Labor Supply Decisions of Young Adults.” Journal of Health Economics. 39: 123-134.

Depew, Briggs and Bailey, James. 2015. "Did the Affordable Care Act's Dependent Coverage Mandate Increase Premiums?” Journal of Health Economics 41: 1-14.

Dillender, Marcus. 2014. "Do More Health Insurance Options Lead to Higher Wages? Evidence from States Extending Dependent Coverage." Journal of Health Economics 36: 84-97.

Finkelstein, Amy, Nathaniel Hendren and Ezro F.P. Luttmer. 2015. The Value of Medicaid: Interpreting Results from the Oregon Health Insurance Experiment. NBER Working Paper 21308.

Garthwaite, Craig, Tal Gross, and Matthew J. Notowidigdo. "Public Health Insurance, Labor Supply, and Employment Lock.” The Quarterly Journal of Economics 129(2): 653-696.

Golberstein, Ezra, Susan H. Busch, Rebecca Zaha, Shelly F. Greenfield, William R. Beardslee, and Ellen Meara. 2014. "The Effect of the Affordable Care Act's Young Adult Insurance 
Expansions on Hospital-Based Behavioral Health Care.” American Journal of Psychiatry. 172(2): 182-9.

Gruber, Jonathan. 1994. "The incidence of Mandated Maternity Benefits." The American Economic Review 84(3): 622-641.

Gruber, Jonathan. (Editor) 2001. "Risky Behavior Among Youth". University of Chicago Press.

Gruber, Jonathan and Brigitte C. Madrian. 1995. "Health-Insurance Availability and The Retirement Decision.” American Economic Review 85(4): 938-948.

Gruber, Jonathan and Brigitte C. Madrian. 2004. "Health Insurance, Labor Supply, and Job Mobility: A Critical Review of the Literature." in McLaughlin, C. (ed.), Health Policy and the Uninsured. Washington, D.C: Urban Institute Press. P..97-177.

Ham, John C. and Lara D. Shore-Sheppard. 2005. "Did Expanding Medicaid Affect Welfare Participation?" Industrial and Labor Relations Review 58(3): 452-470.

Hamersma, Sarah and Matthew Kim. 2009. "The Effect of Parental Medicaid Expansion on Job Mobility." Journal of Health Economics 28 (4): 761-770.

Hahn, Youjin and Hee-Seung Yang. 2016. "Do Work Decisions among Young Adults Respond to Extended Dependent Coverage?" Industrial and Labor Relations Review. 69(3): 737-771.

Heim, Bradley T. and Ithai Z. Lurie. 2010. "The Effect of Self-Employed Health Insurance Subsidies on Self-Employment.” Journal of Public Economics 94(11-12): 995-1007.

Heim, Bradley T. and Ithai Z. Lurie. 2015. "Does Health Reform Lead to Increased Job Mobility? Evidence from Massachusetts." American Journal of Health Economics. 1(3): 374398.

Holtz-Eakin, Douglas, John R. Penrod, and Harvey S. Rosen. 1996. "Health Insurance and the Supply of Entrepreneurs." Journal of Public Economics 62(1-2): 209-235.

Hurst, Erik, Geng Li, and Benjamin Pugsley. 2014. "Are Household Surveys Like Tax Forms? Evidence from Income Underreporting of the Self-Employed." The Review of Economics and Statistics. 96(1):19-33.

Jung, Juergen, Diane M. Hamek Hall, and Thomas Rhoads. 2013. "Does the Availability of Parental Health Insurance Affect the College Enrollment Decision of Young Americans?" Economics of Education Review 32: 49-65.

Kapur, Kanika and Jeannette Rogowski. 2007. "The Role of Health Insurance in Joint Retirement among Married Couples." Industrial and Labor Relations Review 60(3): 397-407. 
Kolstad, Jonathan and Amanda E. Kowalski. 2016. "Mandate Based Health Reform and the Labor Market: Evidence from the Massachusetts Reform.” Journal of Health Economics. 47: 81106.

Madrian, Brigitte C. 1994. "The Effect of Health Insurance on Retirement" Brookings Papers on Economic Activity. 1: 181-232.

Madrian, Brigitte C. 2006. "The U.S. Healthcare System and Labor Markets.” NBER Working Paper 11980.

Madrian, Brigitte C and Lars Lefgren. 1998. "The Effect of Health Insurance on Transitions to Self Employment.” Working Paper.

Monheit, Alan C, Joel C. Cantor, Derek DeLia, and Dina Bello. 2011. "How have State Policies to Expand Dependent Coverage Affected the Health Insurance Status of Young Adults?" Health Services Research 46(1): 251-267.

Mulligan, Casey B. 2013. “Average Marginal Labor Income Tax Rates Under the Affordable Care Act.” NBER Working Paper 19365.

Pew Research Center. 2015. "The Gender Gap in Self-Employment and Hiring." Retrieved from http://www.pewsocialtrends.org/2015/10/22/the-gender-gap-in-self-employment-and-hiring/

Pohl, R. Vincent. 2014. "Medicaid and the Labor Supply of Single Mothers: Implications for Health Care Reform.” Upjohn Institute Working Paper No. 14-222.

Saloner Brendan and Benjamin LeCook. 2014. "An ACA provision increased treatment for young adults with possible mental illnesses relative to comparison group." Health Affairs. 33(8):1425-34.

Slusky, D. Forthcoming. "Significant Placebo Results in Difference-in-Differences Analysis: The Case of the ACA's Parental Mandate". Eastern Economic Journal.

Sommers, Benjamin D., Thomas Buchmueller, Sandra L. Decker, Colleen Carey, and Richard Kronick. 2013. "The Affordable Care Act Has Led to Significant Gains In Health Insurance And Access To Care For Young Adults." Health Affairs 32(1): 165-174.

Strumpf, Erin. 2010. "Employer-Sponsored Health Insurance for Early Retirees: Impacts on Retirement, Health, and Health Care." International Journal of Journal of Health Finance and Economics 10(2): 105-147.

Strumpf, Erin. 2011. “Medicaid's Effect on Single Women's Labor Supply: Evidence from the Introduction of Medicaid." Journal of Health Economics 30(3): 531-548. 
Wellington, Alison J. 2001. "Health Insurance Coverage and Entrepreneurship.” Contemporary Economic Policy. 19(4): 465-478.

Yelowitz, Aaron S. 1995. "The Medicaid Notch, Labor Supply, and Welfare Participation:

Evidence from Eligibility Expansions.” The Quarterly Journal of Economics 110(4): 909-939. 
Table 1. Sample Statistics

\begin{tabular}{|c|c|c|c|c|c|c|}
\hline & \multicolumn{2}{|c|}{ Age 24-29 } & \multicolumn{2}{|c|}{$\begin{array}{c}\text { Age 24-29-Only } \\
\text { Those with } \\
\underline{\text { Retirement Plan }}\end{array}$} & \multicolumn{2}{|c|}{$\begin{array}{l}\frac{\text { Age } 22-29-\text { Only }}{\text { Those with }} \\
\text { Retirement Plan }\end{array}$} \\
\hline & Mean & St. Dev. & Mean & St. Dev. & Mean & St. Dev. \\
\hline \multicolumn{7}{|l|}{ Employment Status } \\
\hline No W-2 Forms & 0.193 & 0.394 & 0.151 & 0.358 & 0.148 & 0.356 \\
\hline Any Self-Employment Income & 0.100 & 0.300 & 0.096 & 0.295 & 0.089 & 0.285 \\
\hline \multicolumn{7}{|l|}{ Job Characteristics } \\
\hline Log Annual Wages & 9.764 & 1.238 & 9.867 & 1.176 & 9.661 & 1.222 \\
\hline Primary-Employer-Offered Health Insurance & 0.462 & 0.499 & 0.502 & 0.500 & 0.498 & 0.500 \\
\hline Retirement Plan at Primary Employer & 0.324 & 0.468 & 0.379 & 0.485 & 0.330 & 0.470 \\
\hline \multicolumn{7}{|l|}{ Educational Enrollment } \\
\hline Post-Secondary Student & 0.194 & 0.396 & 0.217 & 0.412 & 0.288 & 0.453 \\
\hline Full-Time Student & 0.157 & 0.364 & 0.175 & 0.380 & 0.244 & 0.430 \\
\hline Graduate Student & 0.051 & 0.221 & 0.064 & 0.245 & 0.059 & 0.235 \\
\hline \multicolumn{7}{|l|}{ Age } \\
\hline 19 & -- & -- & -- & -- & -- & -- \\
\hline 20 & -- & -- & -- & -- & -- & -- \\
\hline 21 & -- & -- & -- & -- & -- & -- \\
\hline 22 & -- & -- & -- & -- & 0.153 & 0.360 \\
\hline 23 & -- & -- & -- & -- & 0.151 & 0.358 \\
\hline 24 & 0.206 & 0.405 & 0.213 & 0.409 & 0.148 & 0.355 \\
\hline 25 & 0.203 & 0.402 & 0.208 & 0.406 & 0.145 & 0.352 \\
\hline 26 & -- & -- & -- & -- & -- & -- \\
\hline 27 & 0.200 & 0.400 & 0.199 & 0.400 & 0.139 & 0.346 \\
\hline 28 & 0.198 & 0.399 & 0.194 & 0.396 & 0.135 & 0.342 \\
\hline 29 & 0.192 & 0.394 & 0.185 & 0.389 & 0.129 & 0.335 \\
\hline Unemployment Rate & 7.915 & 1.223 & 7.901 & 1.236 & 7.899 & 1.235 \\
\hline \multicolumn{7}{|l|}{ Year } \\
\hline 2008 & 0.192 & 0.394 & 0.199 & 0.399 & 0.199 & 0.399 \\
\hline 2009 & 0.199 & 0.399 & 0.200 & 0.400 & 0.198 & 0.399 \\
\hline 2010 & -- & -- & -- & -- & -- & -- \\
\hline 2011 & 0.201 & 0.401 & 0.200 & 0.400 & 0.200 & 0.400 \\
\hline 2012 & 0.203 & 0.402 & 0.200 & 0.400 & 0.201 & 0.401 \\
\hline 2013 & 0.205 & 0.404 & 0.201 & 0.401 & 0.202 & 0.401 \\
\hline $\mathrm{N}$ & \multicolumn{2}{|c|}{823,249} & \multicolumn{2}{|c|}{452,960} & \multicolumn{2}{|c|}{651,222} \\
\hline
\end{tabular}

Notes: Data from 1\% Sample of Internal Revenue Service (IRS) unedited population files. 
Table 2. Estimation Results

Difference-

Difference-

Employment Status

No W-2 Forms

$\mathrm{N}$

Any Self-Employment Income

$\mathrm{N}$

Job Characteristics

Log Annual Wages

$\mathrm{N}$

Primary-Employer-Offered Health Insurance

$\mathrm{N}$

Retirement Plan at Primary Employer

$\mathrm{N}$ in-

Differences

(1)

DifferenceinDifferences with Controls - only those whose Parents have an EmployerBased Retirement Plan

(3)

(2)

$\begin{array}{ccc}-0.004 & -0.004 * * & -0.002 \\ (0.003) & (0.001) & (0.002) \\ 0.177 & 0.177 & 0.137 \\ 823,249 & 823,249 & 452,960\end{array}$

$\begin{array}{ccc}0.001 & 0.001 & 0.001 \\ (0.003) & (0.001) & (0.001) \\ 0.090 & 0.090 & 0.086 \\ 823,249 & 823,249 & 452,960\end{array}$

$\begin{array}{ccc}-0.022 & -0.018 * * * & -0.009 * * \\ (0.055) & (0.004) & (0.004) \\ 9.571 & 9.657 & 9.657 \\ 664,242 & 664,242 & 384,484\end{array}$

$\begin{array}{ccc}0.005 * & 0.005 * * & 0.004 \\ (0.003) & (0.002) & (0.003) \\ 0.464 & 0.464 & 0.502 \\ 786,949 & 786,949 & 433,320\end{array}$

$\begin{array}{ccc}-0.005 & -0.005 * * * & -0.005 * * * \\ (0.013) & (0.002) & (0.002) \\ 0.296 & 0.296 & 0.342 \\ 823,249 & 823,249 & 452,960\end{array}$




$\begin{array}{lccc}\text { Educational Enrollment } & & & \\ \text { Post-Secondary Student } & 0.000 & -0.002 * & -0.002 * \\ & (0.014) & (0.001) & (0.001) \\ \text { N } & 0.243 & 0.243 & 0.274 \\ & 823,249 & 823,249 & 452,960 \\ \text { Full-Time Student } & & & \\ & 0.004 & 0.001 & 0.005 * * * \\ & (0.013) & (0.001) & (0.001) \\ \text { N } & 0.191 & 0.191 & 0.213 \\ & 823,249 & 823,249 & 452,960 \\ \text { Graduate Student } & & & \\ & 0.002 & 0.002 * & 0.003 * * \\ & (0.002) & (0.001) & (0.001) \\ \text { N } & 0.056 & 0.056 & 0.070 \\ & 823,249 & 823,249 & 452,960\end{array}$

Notes: Data from 1\% Sample of Internal Revenue Service (IRS) unedited population files. Each cell presents results from a separate regression. Standard errors are in parentheses, and the means of the dependent variable among the treatment group in the pre-reform period is in italics. Control variables include indicator variables for year, age, and gender; the unemployment rate; and the interaction between age and the unemployment rate. Standard errors are clustered at the age*year level. Sample includes young adults between the ages of 24 and 29.

*** indicates statistical significance at the $1 \%$ level; ** indicates the $5 \%$ level, and * indicates significance at the $10 \%$ level 
Table 3. Statistical Significance of Difference in Pre-Policy Trends

$\begin{array}{lccc} & \begin{array}{c}\text { Difference-in- } \\ (1)\end{array} & \begin{array}{c}\text { Difference-in- } \\ (2)\end{array} & \begin{array}{c}\text { Difference-in-Differences } \\ (3)\end{array} \\ \text { Employment Status } & 0.001 & 0.001 & -0.002 \\ \text { No W-2 Forms } & (0.004) & (0.004) & (0.004) \\ & -0.002 & -0.002 & -0.003 \\ \text { Any Self-Employment Income } & (0.005) & (0.005) & (0.005) \\ & & & -0.028 \\ \text { Job Characteristics } & -0.015 & -0.014 & (0.087) \\ \text { Log Annual Wages } & (0.087) & (0.086) & 0.004 \\ & 0.001 & 0.001 & (0.006) \\ \text { Primary Employer Offered Health Insurance } & (0.005) & (0.006) & 0.002 \\ & 0.005 & 0.005 & (0.023) \\ \text { Retirement Plan at Primary Employer } & (0.021) & (0.021) & \\ & & & 0.008 \\ \text { Educational Enrollment } & 0.006 & 0.006 & (0.027) \\ \text { Post-Secondary Student } & (0.023) & (0.023) & 0.018 \\ & & 0.016 & (0.023) \\ \text { Full-Time Student } & 0.016 & (0.019) & 0.005 \\ & (0.019) & 0.004 & (0.004)\end{array}$

Notes: Data from $1 \%$ Sample of Internal Revenue Service (IRS) unedited population files. Sample includes young adults between the ages of 24 and 29 during pre-treatment years (20082009). Each cell shows, for the dependent variable given by the row and the specification given by the column, the coefficient and standard error, and whether the outcome in question showed statistically significantly different pre-policy time trends when comparing the treatment group to the control group (i.e. whether the Treatment*PlaceboPost interaction was statistically significant); none of the estimates are statistically significantly different from zero at conventional levels. Control variables include indicator variables for year and gender, and for the unemployment rate. Age indicator variables, and the interaction between age and unemployment rate, are excluded from these tests due to multicollinearity in the limited pre-policy sample period.

*** indicates statistical significance at the $1 \%$ level; ** indicates the $5 \%$ level, and * indicates significance at the $10 \%$ level (Note that none of the estimates are statistically significant in this table.) 
Table 4. Estimation Results - Robustness Check

Base
Specification Ages 22-29
- Ages 24-29

Employment Status

No W-2 Forms

$\begin{array}{cc}-0.002 & -0.002 \\ (0.002) & (0.002) \\ 0.137 & 0.138 \\ 452,960 & 651,222\end{array}$

Any Self-Employment Income

$\begin{array}{cc}0.001 & -0.001 \\ (0.001) & (0.001) \\ 0.086 & 0.081 \\ 452,960 & 651,222\end{array}$

Job Characteristics

Log Annual Wages

$\begin{array}{cc}-0.009 * * & -0.011 * * * \\ (0.004) & (0.004) \\ 9.657 & 9.424 \\ 384,484 & 554,217\end{array}$

Primary Employer Offered Health Insurance

$\begin{array}{cc}0.004 & 0.003 \\ (0.003) & (0.002) \\ 0.502 & 0.498 \\ 433,320 & 622,613\end{array}$

Retirement Plan at Primary Employer

$\begin{array}{cc}-0.005 * * * & -0.003 * \\ (0.002) & (0.002) \\ 0.342 & 0.288 \\ 452,960 & 651,222\end{array}$

Educational Enrollment

Post-Secondary Student

$-0.002 * \quad 0.003$

$(0.001) \quad(0.002)$

$0.274 \quad 0.360$

$\mathrm{N}$

$452,960 \quad 651,222$

Full-Time Student

$0.005 * * * \quad 0.011 * * *$ 


$\begin{array}{lcc} & (0.001) & (0.003) \\ \mathrm{N} & 0.213 & 0.298 \\ & 452,960 & 651,222 \\ \text { Graduate Student } & & \\ & 0.003 * * & 0.002 \\ & (0.001) & (0.001) \\ \mathrm{N} & 0.07 & 0.057 \\ & 452,960 & 651,222\end{array}$

Notes: Data from 1\% Sample of Internal Revenue Service (IRS) unedited population files.

Model estimated is difference-in-differences with controls in which the sample includes those whose parents had a retirement plan. Each cell presents results from a separate regression.

Control variables include indicator variables for year, age and gender, the unemployment rate, and the interaction between age and the unemployment rate. Standard errors are in parentheses, and the means of the dependent variable among the treatment group in the pre-reform period is in italics. Standard errors are clustered at the age* year level.

$* * *$ indicates statistical significance at the $1 \%$ level; ** indicates the $5 \%$ level, and * indicates significance at the $10 \%$ level 
Table 5. Estimation Results - By Gender

Men Women

(1) (2)

Employment Status

No W-2 Forms

$-0.003 \quad 0.000$

$(0.003) \quad(0.002)$

$0.140 \quad 0.135$

$\mathrm{N}$

$232,311 \quad 220,649$

Any Self-Employment Income

$0.004 * \quad-0.001$

$(0.002) \quad(0.002)$

$0.093 \quad 0.079$

$\mathrm{N}$

$232,311 \quad 220,649$

Job Characteristics

Log Annual Wages

$0.006-0.025 * * *$

(0.007) (0.004)

$9.704 \quad 9.609$

$\mathrm{N}$

$198,301 \quad 186,183$

Primary Employer Offered Health Insurance

$0.010 * * \quad 0.002$

(0.004) (0.001)

$0.473 \quad 0.532$

$\mathrm{N}$

$221,786 \quad 220,649$

Retirement Plan at Primary

Employer

$-0.003 \quad-0.007 * *$

(0.002) (0.003)

$0.340 \quad 0.344$

$\mathrm{N}$

$232,311 \quad 220,649$

Educational Enrollment

Post-Secondary Student

$-0.002 \quad-0.002$

$(0.002) \quad(0.002)$

$0.238 \quad 0.311$

$\mathrm{N}$

$232,311 \quad 220,649$

Full-Time Student

$0.002^{* *} \quad 0.007 * * *$ 
$(0.001) \quad(0.002)$

$0.186 \quad 0.242$

$\mathrm{N}$

$232,311 \quad 220,649$

Graduate Student

$0.003 * * * \quad 0.004$

$(0.001) \quad(0.003)$

$0.052 \quad 0.089$

$\mathrm{N}$

$232,311 \quad 220,649$

Notes: Data from 1\% Sample of Internal Revenue Service (IRS) unedited population files. Model estimated is difference-in-differences with controls in which the sample includes those whose parents had a retirement plan. Each cell presents results from a separate regression. Control variables include indicator variables for year, age and gender, the unemployment rate, and the interaction between age and the unemployment rate. Standard errors are in parentheses, and the means of the dependent variable among the treatment group in the pre-reform period is in italics. Standard errors are clustered at the age*year level. Sample includes young adults between the ages of 24 and 29.

$* * *$ indicates statistical significance at the $1 \%$ level; ** indicates the $5 \%$ level, and * indicates significance at the $10 \%$ level 
Table 6. Estimation Results - By Income Level

$\begin{array}{cccc}\text { Income }< & \begin{array}{c}125 \% \mathrm{FPL} \\ <\text { Income }<\end{array} & \begin{array}{c}250 \% \mathrm{FPL} \\ <\text { Income }<\end{array} & \begin{array}{c}\text { Income }> \\ 125 \% \mathrm{FPL}\end{array} \\ 250 \% \mathrm{FPL} & 400 \% \mathrm{FPL} & 400 \% \mathrm{FPL} \\ (1) & (2) & (3) & (4)\end{array}$

Employment Status

No W-2 Forms

$\mathrm{N}$

Any Self-Employment Income

$\mathrm{N}$

Job Characteristics

Log Annual Wages

$\mathrm{N}$

-0.006
$(0.006)$
0.207

52,579

$$
\begin{gathered}
-0.006 * * \\
(0.002) \\
0.085 \\
52,579
\end{gathered}
$$

0.007

(0.017)

9.348

40,813

Primary Employer Offered

Health Insurance

$\mathrm{N}$

Retirement Plan at Primary

Employer

$\mathrm{N}$

$$
\begin{gathered}
0.019 * * * \\
(0.006) \\
0.448 \\
50,300
\end{gathered}
$$

$$
\begin{gathered}
0.009 * \\
(0.005) \\
0.249 \\
52,579
\end{gathered}
$$

Educational Enrollment

Post-Secondary Student

$\mathrm{N}$

Full-Time Student

$$
\begin{gathered}
0.007 * * \\
(0.003) \\
0.194 \\
52,579
\end{gathered}
$$

$0.008 * * *$

$-0.005^{*}$
$(0.003)$
0.158
111,365

111,365

$$
0.002
$$

(0.002)

0.077

111,365

$-0.011$

(0.008)

9.548

92,002

$0.007 * *$

(0.003)

0.476

106,612

$$
\begin{gathered}
-0.005 \\
(0.004) \\
0.303
\end{gathered}
$$

111,365

$-0.011$

(0.010)

$-0.026^{* *}$

9.694

(0.010)

117,256

9.797

134,413

$\begin{array}{cc}0.002 & -0.004 \\ (0.004) & (0.004) \\ 0.514 & 0.527 \\ 129,611 & 146,797\end{array}$

$\begin{array}{cc}-0.011 * * & -0.009 * * * \\ (0.004) & (0.002) \\ 0.362 & 0.384 \\ 135,592 & 153,424\end{array}$

$$
\begin{gathered}
-0.012 * * * \\
(0.002) \\
0.231 \\
111,365
\end{gathered}
$$

0.005

0.001

(0.003)

(0.001)

0.273

0.332

135,592

153,424

$-0.004$

$0.013 * * *$

$0.007 * * *$ 


$\begin{array}{lcccc} & (0.003) & (0.002) & (0.003) & (0.002) \\ \mathrm{N} & 0.153 & 0.180 & 0.213 & 0.259 \\ & 52,579 & 111,365 & 135,592 & 153,424 \\ \text { Graduate Student } & & & & \\ & 0.000 & 0.001 & 0.010 * * * & 0.003 \\ & (0.002) & (0.001) & (0.003) & (0.002) \\ \mathrm{N} & 0.024 & 0.037 & 0.061 & 0.118 \\ & 52,579 & 111,365 & 135,592 & 153,424\end{array}$

Notes: Data from 1\% Sample of Internal Revenue Service (IRS) unedited population files. Model estimated is difference-in-differences with controls in which the sample includes those whose parents had a retirement plan. Each cell presents results from a separate regression. Control variables include indicator variables for year, age and gender, the unemployment rate, and the interaction between age and the unemployment rate. Standard errors are in parentheses, and the means of the dependent variable among the treatment group in the pre-reform period is in italics. Standard errors are clustered at the age*year level. Sample includes young adults between the ages of 24 and 29.

*** indicates statistical significance at the $1 \%$ level; ** indicates the $5 \%$ level, and * indicates significance at the $10 \%$ level 
Table 7: Comparisons to Largest Estimates in Literature

\begin{tabular}{|c|c|c|c|c|c|c|}
\hline$\frac{\text { Labor Market }}{\underline{\text { Oucome }}}$ & Specification & 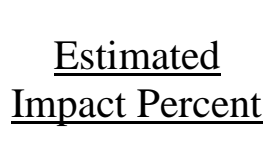 & $\frac{\text { Coverage }}{\underline{\text { Percent }}}$ & $\underline{\text { Implied }}$ & $\frac{\frac{\text { Largest }}{\text { Estimate in }}}{\text { Literature }}$ & $\underline{\text { Paper }}$ \\
\hline No W-2 Forms & Age $24-29$ & $1.5^{*}$ & 30 & 0.05 & 0.63 & Garthwaite et al. (2014) \\
\hline $\begin{array}{l}\text { Any Self- } \\
\text { Employment } \\
\text { Income }\end{array}$ & $\begin{array}{l}\text { Age } 24-29 \\
\text { Men }\end{array}$ & 4.3 & 30 & 0.14 & 0.80 & Bailey (Forthcoming) \\
\hline $\begin{array}{l}\text { Log Annual } \\
\text { Wages }\end{array}$ & Age 24-29 & -0.9 & 30 & -0.03 & -0.20 & Dague et al. (2014) \\
\hline $\begin{array}{l}\text { Full-Time } \\
\text { Student }\end{array}$ & Age 24-29 & 2.3 & 30 & 0.08 & 0.22 & Jung et al. (2013) \\
\hline
\end{tabular}

Note: The 30 percent increase in dependent coverage estimate comes from Akosa Antwi et al. (2013). The estimate of 0.8 for Bailey (2014) comes from taking the $24 \%$ upper end increase estimate in Bailey (Forthcoming) and dividing it by the $30 \%$ increase in dependent coverage from Akosa Antwi et al. (2013).

* Not statistically different from 0 at conventional significance levels. 
Appendix Table 1: Age of Birth Cohort by Year of Tax Data

\begin{tabular}{cccc} 
& \multicolumn{3}{c}{ Birth Cohort } \\
\cline { 2 - 4 } Tax Year & $\frac{1995}{9}$ & $\ldots$ & $\frac{1979}{25}$ \\
2004 & & & 26 \\
2005 & 10 & & 27 \\
2006 & 11 & & 28 \\
2008 & 12 & & 29 \\
$\ldots$ & 13 & & \\
2012 & 17 & & 33 \\
2013 & 18 & & 34
\end{tabular}

Note: Oldest age of dependent is assumed to be 18 in 1997, thus in the 1979 cohort. Italics show what we would have if we expanded years of data to before 2005. The last year back in time for which we would have 27-29 year olds represented is 2008 . If we go back past 2006, we would not have any age in the control age range. 
Appendix Table 2: Sample Sizes by Age and Year

\begin{tabular}{cccccc} 
& \multicolumn{5}{c}{ Year } \\
\cline { 2 - 6 } Age & $\underline{2008}$ & $\underline{2009}$ & $\underline{2010}$ & $\underline{2011}$ & $\underline{\underline{2012}}$ \\
22 & 33,176 & 33,981 & 34,323 & 35,453 & 36,457 \\
23 & 33,353 & 33,176 & 33,981 & 34,323 & 35,453 \\
24 & 32,756 & 33,353 & 33,176 & 33,981 & 34,323 \\
25 & 32,678 & 32,756 & 33,353 & 33,176 & 33,981 \\
26 & 33,120 & 32,678 & 32,756 & 33,353 & 33,176 \\
27 & 32,441 & 33,120 & 32,678 & 32,756 & 33,353 \\
28 & 31,961 & 32,441 & 33,120 & 32,678 & 32,756 \\
29 & 27,952 & 31,961 & 32,441 & 33,120 & 32,678
\end{tabular}

Note: Data from 1\% Sample of Internal Revenue Service (IRS) unedited population files. Data from 2010, and data for 26 year olds, are not used in the differences calculations. 